\title{
Follicular Fluid Activin A and Leptin are not Correlated with IVF Outcome Measures
}

\author{
Mohamed M Shaaban ${ }^{1}$, Waleed S Ahmed ${ }^{1 *}$, Iman Keshk ${ }^{1}$ and Hossam El Bahaie ${ }^{2}$ \\ ${ }^{1}$ Department of Obstetrics and Gynecology, Suez Canal University, Egypt \\ ${ }^{2}$ Department of clinical pathology, Suez Canal University, Egypt
}

\begin{abstract}
Objective: The present study is designed to prospectively evaluate relationship between follicular fluid (FF) Leptin and Activin A and IVF outcome measures.

Design: Prospective observational study.

Population: FF Leptin and Activin A were measured in 90 patients undergoing ICSI cycles excluding polycystic ovarian syndrome (PCOS) patients. Follicular fluid samples collected at oocyte retrieval from follicles $\geq 18 \mathrm{~mm}$ in diameter were analyzed for Leptin and Activin A using enzyme-linked immunosorbent assay (ELISA) and results were correlated to ICSI outcome.
\end{abstract}

Main outcome measures: FF leptin and activin A levels, fertilization and pregnancy rates.

Results: For the whole population (90 patients), mean follicular fluid Leptin level was $45.2 \pm 26.7 \mathrm{ng} / \mathrm{ml}$ and mean body mass index was $25.3 \pm 3.3 \mathrm{~kg} / \mathrm{m}^{2}$. FF Leptin had a positive correlation with $\mathrm{BMI}(\mathrm{p}<0.005)$. The mean FF Activin A was $880.8 \pm 354.6 \mathrm{pg} / \mathrm{ml} 29 / 90$ patients $(32.2 \%)$ achieved pregnancy, twenty five of them $(86.2 \%)$ had more than $50 \%$ grade $A$ embryos on day 2 in contrast to 33 patients $(54.1 \%)$ in the non-pregnant group $(P<0.02)$, this means that pregnancy was positively correlated to day 2 embryo quality. FF Leptin and Activin A did not correlate to day 2 embryo qualities or pregnancy outcome.

FF total Activin A level did not relate to FF Leptin level or number of oocytes collected. Low or high FF Activin A or Leptin levels did not show an effect on fertilization, pregnancy or day 2 embryo qualities.

Conclusion: Neither FF Activin A nor FF Leptin levels can be used to predict IVF outcome measures.

Keywords: Activin A; Leptin; Follicular fluid; Intracytoplasmic sperm injection; Pregnancy

Abbreviations: FF: Follicular Fluid; PCOS: Polycystic Ovarian Syndrome; ELISA: Enzyme-Linked Immunosorbent Assay

\section{Introduction}

Assisted reproduction is a complicated process involving multiple stages of ovarian stimulation, ovum pick up, fertilization, embryo cleavage and implantation. The ultimate goal of all these procedures is achievement of a viable intra uterine pregnancy as a step of achievement of a healthy baby. Good quality of all reproductive components and primarily embryos has a positive impact on success rates. Definitely, better selection of embryos is one of the greatest challenges in IVF [1]. A morphological approach of choosing good quality embryos at 2-8 cell stage based on number, equality of size and percent fragmentation $[2,3]$ has been the method of choice of day 2 or 3 embryo transfer [4].

Activins are disulphide-linked dimeric glycoproteins belonging to the TGF-b super family. Other members include inhibin and follistatin. While inhibin and activin exert their actions mainly through a negative feedback effect on pituitary FSH, activins, mainly activin A exert their effects through local autocrine and paracrine effects on granulosa cells through action on specific receptors $[5,6]$. Once granulosa cells have acquired functional FSH receptors, their proliferation and differentiation would be driven mainly by FSH, but modulated by other extrinsic and locally produced factors including insulin, growth hormone and leptin [7].

Leptin, a protein secreted from adipose and many other tissues of mammals was found to a greater extent in people with a high body mass index [8]. Leptin was shown to be involved in various reproductive aspects including initiation of puberty, fertility and pregnancy. Serum leptin at various stages of IVF cycles, in addition to follicular fluid leptin were suggested as predictors for IVF outcome with some conflicting results. Anifandis et al. [9] reported that elevated follicular fluid leptin concentration was associated with reduced ovarian response, follicle maturation, embryo quality and response [9]; however, others failed to prove those associations $[10,11]$.

The aim of this work is to study a correlation between follicular fluid activin A and leptin and the various IVF outcome measures including oocyte number, fertilization rate, good embryo quality rate and pregnancy rate.

\section{Subjects and Methods}

The study was carried out in a private IVF center setting in Cairo, Egypt. Patients less than 42 years with day 2-3 FSH $<10$ IU/L were

*Corresponding author: Waleed S Ahmed, Assistant Professor, Department of Obstetrics and Gynecology, Suez Canal University, Ismailia, Egypt, Tel: 0020663334230; E-mail: waleed.asa@gmail.com

Received September 24, 2012; Accepted November 26, 2012; Published November 30, 2012

Citation: Shaaban MM, Ahmed WS, Keshk I, Bahaie HE (2013) Follicular Fluid Activin A and Leptin are not Correlated with IVF Outcome Measures. J Steroids Horm Sci 4: 111. doi:10.4172/2157-7536.1000111

Copyright: (c) 2013 Shaaban MM, et al. This is an open-access article distributed under the terms of the Creative Commons Attribution License, which permits unrestricted use, distribution, and reproduction in any medium, provided the original author and source are credited. 
included in the study excluding patients with polycystic ovarian syndrome to nullify its effect on follicular development and IVF outcome. Ninety women were included in the study after signing initial relevant consents and after obtaining the ethical approval from the faculty ethical committee. All women had long protocol ICSI cycles. They received GnRHa in the form of $0.1 \mathrm{mg}$ triptorelin acetate as daily subcutaneous injection starting on mid-luteal phase of the cycle and it was continued until loss of follicular activity by transvaginal ultrasonography. Exogenous gonadotropins were initiated and triptorelin acetate was decreased to half on second day of menstruation. When $\geq 3$ follicles reached $18 \mathrm{~mm}$ diameter or more, a single 10,000 IU intramuscular dose of hCG was administered. Transvaginal follicular aspiration took place 35-36 hours later under sedation/general anesthesia.

All large mature follicles $(>18 \mathrm{~mm})$ were aspirated into empty sterile tubes and samples with blood contamination or with flushing fluid were excluded. The follicular fluid was used only if it contains good quality (grade I) oocyte and FF was centrifuged at $1500 \mathrm{rpm}$ for 15 minutes and the supernatants were frozen at $-70^{\circ} \mathrm{C}$ for future analysis [5]. ELISA tests were used for measuring leptin and activin A as described elsewhere [5,12]. BMI was evaluated on day of oocyte recovery. Standard ICSI procedure for all cases as per the IVF center protocol was carried out only to metaphase II (M II) oocytes with daily evaluation of fertilization and embryo grading. Embryos were graded on day 2 and 3 according to the number of blastomeres $(<5$ or $>5)$, equality of size and degree of fragmentation, giving a score of 1 or 2 for each item. Embryos were scored 'A' for those achieving a score of 5-6 and ' $\mathrm{B}$ ' for those scoring less.

For statistical purposes, day 2 embryo quality was considered good when the majority of embryos were grade $A$ and poor when the majority was grade B. Two embryos (or 3 embryos in women over 40 years) were transferred in early (day 2or 3) and late (day 5) ET respectively. ET was performed using labotect catheter (Germany) under ultrasound guidance. Luteal phase support was achieved by $400 \mathrm{mg}$ vaginal progesterone. Pregnancy was confirmed by quantitative $\beta$-hCG after 2 weeks of oocyte retrieval followed by sonographic confirmation of cardiac activity 2 weeks later.

SPSS 19 package (SPSS, Chicago, IL, USA) was used for statistical analysis. Data was expressed as means $\pm \mathrm{SD}$. Student $t$, chi square and Pearson correlation test were used when appropriate. Significant values were set at $\mathrm{p}<0.05$ level.

\section{Results}

A total of 90 women were counseled, consented, and enrolled into the study from October 2010 till April 2011. There were no patient drop-outs or cycle cancellation. The indications for treatment were: Male factor: 34 patients (37.7\%), tubal factor: 14 patients $(15.5 \%)$, endometriosis: 12 patients (13.3\%), unexplained infertility: 18 patients (20\%) and combined factors: 12 patients (13.3\%).The whole study group age ranged between 23 to 41 years with a mean of $29.6 \pm 5.1$ years. All women were nulliparous. No difference in the total dose of gonadotropins was found between the pregnant and the non-pregnant groups.

For the whole group, mean follicular fluid (FF) leptin level was 45.2 $\pm 26.7 \mathrm{ng} / \mathrm{ml}$ and BMI was $25.3 \pm 3.3 \mathrm{~kg} / \mathrm{m}^{2}$. FF leptin had a positive correlation with body mass index $(\mathrm{r}=0.4, \mathrm{p}<0.005)$ (Figure 1$)$.

Mean follicular fluid activin was $880.8 \pm 354.6 \mathrm{pg} / \mathrm{ml}$. No differences in follicular fluid leptin or follicular fluid activin A were

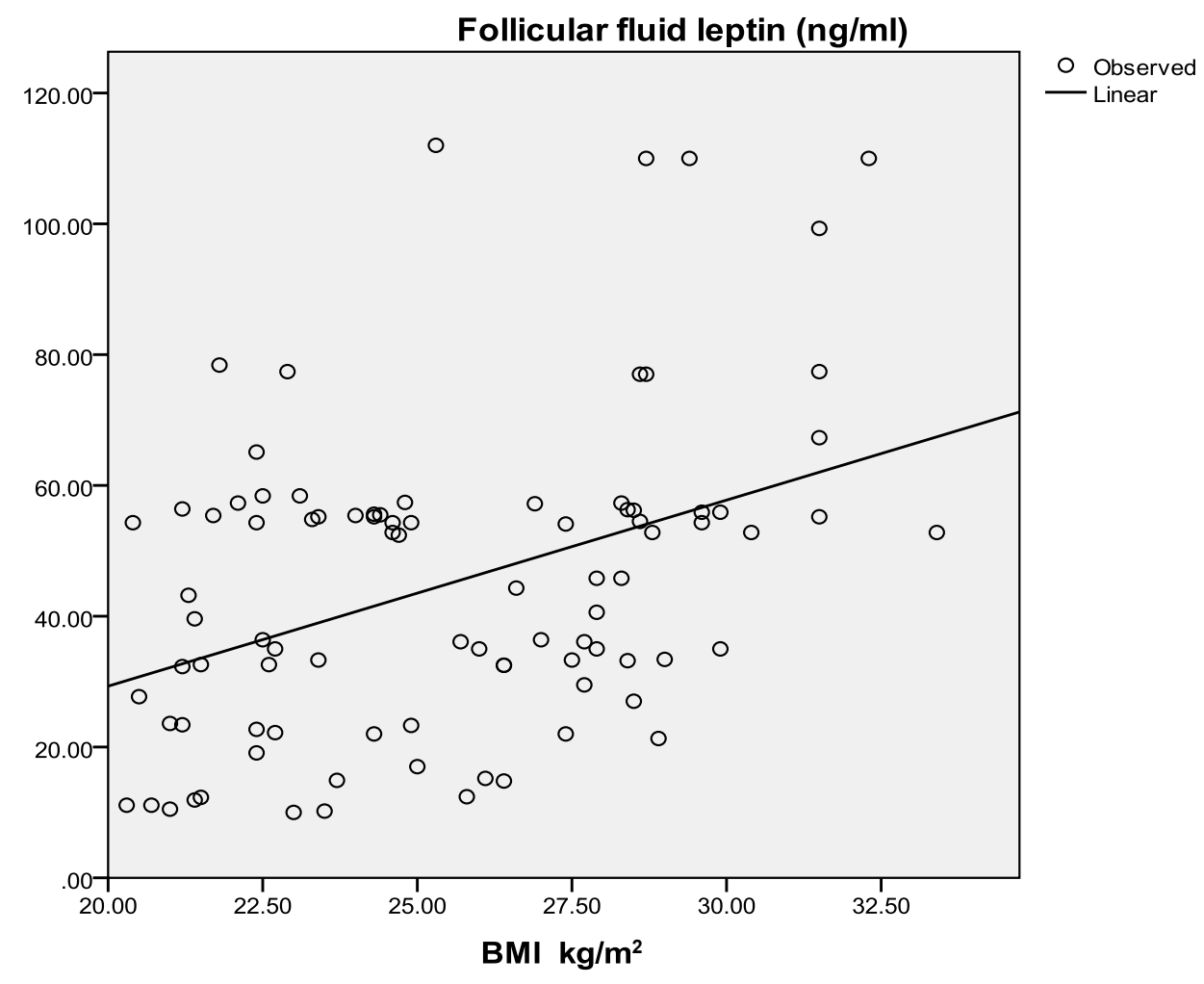

Figure 1: Correlation between follicular fluid leptin concentration and BMI. 
Citation: Shaaban MM, Ahmed WS, Keshk I, Bahaie HE (2013) Follicular Fluid Activin A and Leptin are not Correlated with IVF Outcome Measures. J Steroids Horm Sci 4: 111. doi:10.4172/2157-7536.1000111

Page 3 of 5

shown different infertility categories included (Table 1). No correlation between follicular fluid activin and oocyte number (Pearson correlation: $0.089 \mathrm{p}=0.4$ ) or follicular fluid leptin (Pearson correlation: 0.15 $\mathrm{p}=0.15$ ).

Pregnancy rate for the whole group was 32.2\% (29/90). Table 2 shows patient characteristics in pregnant and non-pregnant groups. No significant differences were shown regarding age, duration of infertility. Body mass index, follicular fluid leptin or activin as well as fertilization rate were not significantly different in the two groups. The only significant difference was in the pregnant group having significantly better quality embryos on day $2(\mathrm{p}=0.02)$.

Looking at the embryo quality, follicular fluid leptin and activin were not significantly different in the two groups of 'good' or 'bad' embryo quality on day 2 ; $(34.4 \pm 21.5$ vs. $37.2 \pm 20.7 \mathrm{ng} / \mathrm{ml}$ for leptin and $825.2 \pm 725.4$ and $895.4 \pm 312.3$ for activin $\mathrm{A}, \mathrm{P}=0.5$ and 0.62 respectively).

The data were classified according to follicular fluid leptin of $\leq$ and $>60 \mathrm{ng} / \mathrm{ml}$ into low and high FF leptin respectively (Table 3 ). There were no significant differences between the two subgroups as regards to patients' age or duration of infertility, number of oocytes retrieved, fertilization rate, good quality embryo rate and pregnancy rate. Also, mean FF activin was not significantly different between the two subgroups.

Similarly, the data were classified according to follicular fluid activin of $\leq$ and $>1000 \mathrm{pg} / \mathrm{ml}$ into low and high FF activin respectively (Table
3).There were no significant differences between the two subgroups as regards to patients' age or duration of infertility, number of oocytes retrieved, fertilization rate, good quality embryo rate and pregnancy rate. Also, mean FF Leptin was not significantly different between the two subgroups.

Figures 2 and 3 shows the distribution of pregnancy among patients with different levels of Leptin and Activin A respectively. The occurrence of pregnancy did not correlate to the level of the hormones.

\section{Discussion}

Leptin and activin are two hormones that do have some role in folliculogenesis and the local regulations of follicular development and therefore were studied to try to prove or not any association between them and the ART parameters and outcome. Ninety patients were enrolled, of them 29 (32.2\%) achieved pregnancy. Patients' characteristics were similar in the pregnant and non-pregnant groups as regards to age, duration of infertility and body mass index. The only significant difference was in the pregnant group having significantly better quality embryos on day 2 which was in accordance with other studies [2,3]. Consistent with other studies [13,14]; follicular fluid leptin was positively correlated with BMI. It was also noted that follicular fluid leptin and activin A did not differ significantly in patients undergoing ICSI treatment for different indications i.e. tubal factor, unexplained infertility, etc.

\begin{tabular}{|l|l|l|l|l|l|l|}
\hline & Endometriosis & Tubal & Male & Unexplained Infertility & Combined Factors & P value \\
\hline FF Leptin & $39.1 \pm 20.1$ & $52.7 \pm 31.1$ & $42.2 \pm 25.1$ & $30.2 \pm 19.3$ & $37.1 \pm 13.3$ \\
\hline FF Activin A & $1049.3 \pm 347.2$ & $781.5 \pm 329.4$ & $769.3 \pm 360.8$ & $811.6 \pm 267.8$ & 1 \\
\hline
\end{tabular}

Data expressed as means \pm standard deviation

Table 1: FF leptin and activin A in different infertility categories.

\begin{tabular}{|c|c|c|c|c|}
\hline & Pregnant $(\mathrm{N}=29)$ & Not pregnant $(\mathrm{N}=61)$ & All patients $(\mathrm{N}=90)$ & ${ }^{*} \mathbf{P}$ value \\
\hline Age (years) ${ }^{* \star}$ & $28.9 \pm 4.6$ & $30.3 \pm 5.3$ & $29.6 \pm 5.1$ & 0.61 \\
\hline Months of Infertility ** & $54.6 \pm 23.6$ & $57.8 \pm 29.5$ & $56.7 \pm 27.6$ & 0.64 \\
\hline $\operatorname{BMI}\left(\mathrm{kg} / \mathrm{m}^{2}\right)^{* *}$ & $24.9 \pm 3.6$ & $25.7 \pm 3.1$ & $25.5 \pm 3.3$ & 0.25 \\
\hline FF leptin $(\mathrm{ng} / \mathrm{ml})^{\star *}$ & $43.5 \pm 24.8$ & $45.7 \pm 23.1$ & $45.2 \pm 26.7$ & 0.62 \\
\hline Activin A (pg/ml) $)^{\star *}$ & $782.2 \pm 368.2$ & $925.2 \pm 338.3$ & $880.8 \pm 354.6$ & 0.53 \\
\hline Day 2 good emb. quality & $25(86.2 \%)$ & $33(54.1 \%)$ & $58(64.4 \%)$ & $0.02(\mathrm{~S})$ \\
\hline Fertilization rate ${ }^{* *}$ & $65.7 \pm 12.7$ & $65.8 \pm 22.2$ & $65.7 \pm 19.7$ & 0.90 \\
\hline
\end{tabular}

${ }^{* *}$ mean $\pm \mathrm{SD}$

S: Significant at 0.05 level

$\mathrm{BMI}=$ Body Mass Index; FF = Follicular Fluid

Table 2: patient characteristics according to pregnancy state.

\begin{tabular}{|c|c|c|c|c|c|c|}
\hline & \multicolumn{3}{|l|}{ Leptin (ng/ml) } & \multicolumn{3}{|c|}{ Total Activin A (pg/ml) } \\
\hline & $($ no $=74)$ & $($ no $=16)$ & *P value & $(\mathrm{no}=65)$ & (no = 25) & *P value \\
\hline Age (years) ${ }^{\star *}$ & $30.3 \pm 5.7$ & $29.6 \pm 5.1$ & 0.7 & $31.6 \pm 5.7$ & $28.9 \pm 5.1$ & 0.5 \\
\hline Months of Infertility ** & $50.2 \pm 22.3$ & $55.4 \pm 24.3$ & 0.4 & $52.2 \pm 23.6$ & $54.8 \pm 21.3$ & 0.4 \\
\hline No. of oocytes collected ** & $10.09 \pm 5.5$ & $11.88 \pm 6.5$ & 0.9 & $12.95 \pm 5.3$ & $11.8 \pm 7.2$ & 0.67 \\
\hline Fertilization rate ${ }^{* *}$ & $65.6 \pm 20.7$ & $62.9 \pm 23.5$ & 0.6 & $64.6 \pm 21.7$ & $65.7 \pm 16$ & 0.83 \\
\hline Day 2 good emb. quality & $50(67.5 \%)$ & $8(50 \%)$ & 0.1 & $41(63 \%)$ & $17(68 \%)$ & 0.63 \\
\hline Pregnancy & $25(33.8 \%)$ & $4(25 \%)$ & 0.1 & $23(35.3 \%)$ & $6(24 \%)$ & 0.09 \\
\hline FF level ** & $\begin{array}{l}\text { FF Activin } \\
904.3 \pm 442\end{array}$ & $\begin{array}{l}\text { FF Activin } \\
796 \pm 491\end{array}$ & 0.2 & $\begin{array}{l}\text { FF Leptin } \\
36.9 \pm 28.5\end{array}$ & $\begin{array}{l}\text { FF Leptin } \\
27.3 \pm 14.1\end{array}$ & 0.1 \\
\hline
\end{tabular}

*Significant at 0.05 level

${ }^{* *}$ mean \pm SD

Table 3: Low and high leptin and activin A in the study group. 


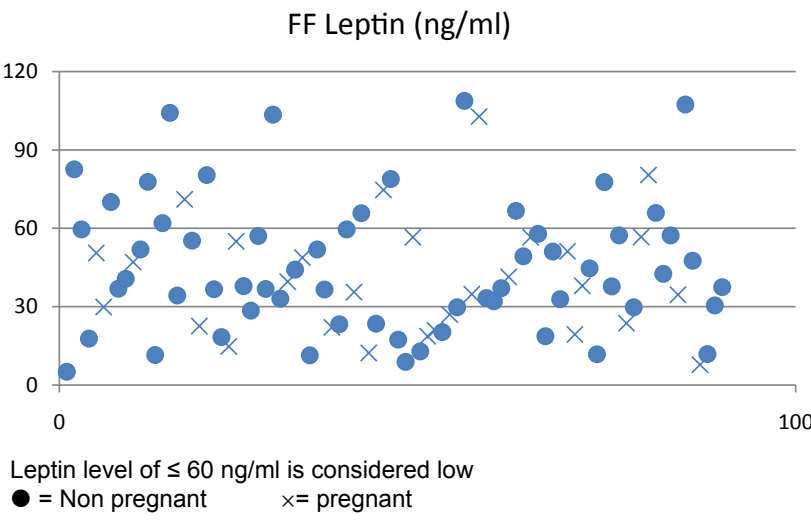

Figure 2: Low and high follicular fluid Leptin and pregnancy.

FF Total Activin A (pg/ml)

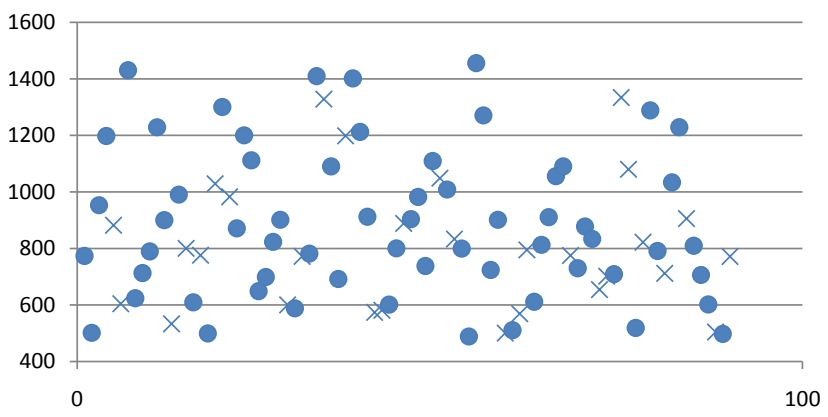

Activin A level of $\leq 1000 \mathrm{pg} / \mathrm{ml}$ is considered low

- Non pregnant $\quad x=$ pregnant

Figure 3: Low and high follicular fluid Activin A and pregnancy.

Follicular fluid leptin was not found to be correlated with pregnancy or indeed any other ART outcome measures. This result was observed in other studies $[10,15]$ although other investigators reported an association between FF leptin and IVF/ICSI outcome [9,16,17]. Leptin can affect follicular development through a central (hypothalamicpituitary) and end organ (ovary and endometrium) effects [18]

When the group was further divided to those with high and low FF leptin ( $\leq$ and $>60 \mathrm{ng} / \mathrm{ml}$ ) - this cut of point was based on the observation by Anifandis et al. [19] that below this level poor embryo quality and IVF failure are expected, there was no significant differences between the two subgroups as regards to the outcome measures namely fertilization, pregnancy or day 2 good embryo quality rates. This was consistent with other reports $[10,11]$

Lau et al. [20] found that level of Activin A was higher in follicles containing good quality oocytes, however this increase did not reach significant difference and failed to show an association with the fertilizing ability of the oocytes [20]. We tested this hypothesis by measuring the level of Activin A in large follicles containing good quality oocytes. There was no significant difference in Activin A levels in pregnant and non-pregnant groups.

The group was further classified into low and high Activin A level subgroups for those having FF activin $\mathrm{A} \leq$ and $>1000 \mathrm{pg} / \mathrm{ml}$ respectively - the choice of the cut of point $1000 \mathrm{pg} / \mathrm{ml}$ was based on results by Lau et al. [20] who found mean FF activin A with high quality embryos was close to this level-, again, there were no significant differences in any of the outcome measures namely fertilization, pregnancy or day 2 good embryo quality rate. This could be explained by the fact that available Activin A is tightly bound to follistatin, a cysteine rich glycoprotein locally secreted by theca cells that was found to have a high binding affinity to Activin A [7] and was suggested to neutralize its biological activity in distant target tissues [21]. Our results suggest that this binding affinity is also functioning in local follicular fluid medium.

A hypothesis that follicular fluid Activin A affects follicular fluid Leptin synthesis was tested. We failed to find a correlation between FF Activin A and Leptin levels. Whether there was actual no relation or an effect is neutralized by follistatin binding requires further validation by testing the effect of purified FF Activin A on FF Leptin.

In conclusion, the local hormonal milieu in the ovary can only be examined by measurement of follicular fluid hormones. This can give us an idea about the hormonal influence on the developing follicles subjected to the controlled ovarian stimulation. In our study, there was no correlation between FF Activin A, Leptin and the IVF outcome measures as well as between FF Activin A and Leptin.

\section{Acknowledgements}

This research did not receive any specific grant from any funding agency in the public, commercial or not-for-profit sector. The authors sincerely appreciate the help of Prof Mohamed A Motawae for his kind assistance.

\section{References}

1. Plachot M (1989) Choosing the right embryo: the challenge of the nineties. $\mathrm{J}$ In Vitro Fert Embryo Transf 6: 193-194.

2. Cummins JM, Breen TM, Harrison KL, Shaw JM, Wilson LM, et al. (1986) A formula for scoring human embryo growth rates in in vitro fertilization: its value in predicting pregnancy and in comparison with visual estimates of embryo quality. J In Vitro Fert Embryo Transf 3: 284-295.

3. Puissant F, Van Rysselberge M, Barlow P, Deweze J, Leroy F (1987) Embryo scoring as a prognostic tool in IVF treatment. Hum Reprod 2: 705-708.

4. Lundqvist M, Rova K, Simberg N, Lundkvist O (2002) Embryo transfer after 2 or 5 days of IVF culture: a retrospective comparison. Acta Obstet Gynecol Scand 81: 126-132.

5. Miró F, Hillier SG (1992) Relative effects of activin and inhibin on steroid hormone synthesis in primate granulosa cells. J Clin Endocrinol Metab 75 1556-1561.

6. de Kretser DM, Meinhardt A, Meehan T, Phillips DJ, O'Bryan MK, et al. (2000) The roles of inhibin and related peptides in gonadal function. Mol Cell Endocrinol 161: 43-46.

7. Knight PG, Glister C (2001) Potential local regulatory functions of inhibins, activins and follistatin in the ovary. Reproduction 121: 503-512.

8. Garcia-Mayor RV, Andrade MA, Rios M, Lage M, Dieguez C, et al. (1997) Serum leptin levels in normal children: relationship to age, gender, body mass index, pituitary-gonadal hormones, and pubertal stage. J Clin Endocrinol Metab 82: 2849-2855

9. Anifandis G, Koutselini E, Stefanidis I, Liakopoulos V, Leivaditis C, et al. (2005) Serum and follicular fluid leptin levels are correlated with human embryo quality. Reproduction 130: 917-921.

10. Chen R, Fisch B, Ben-Haroush A, Kaplan B, Hod M, et al. (2004) Serum and follicular fluid leptin levels in patients undergoing controlled ovarian hyperstimulation for in vitro fertilization cycle. Clin Exp Obstet Gynecol 31: 103106.

11. Hill MJ, Uyehara CF, Hashiro GM, Frattarelli JL (2007) The utility of serum leptin and follicular fluid leptin, estradiol, and progesterone levels during an in vitro fertilization cycle. J Assist Reprod Genet 24: 183-188.

12. Muttukrishna S, Groome N, Ledger W (1997) Gonadotropic control of secretion of dimeric inhibins and activin A during the human menstrual cycle and pregnancy. J Clin Endocrinol Metab 81: 3328-3334. 
Citation: Shaaban MM, Ahmed WS, Keshk I, Bahaie HE (2013) Follicular Fluid Activin A and Leptin are not Correlated with IVF Outcome Measures. J Steroids Horm Sci 4: 111. doi:10.4172/2157-7536.1000111

Page 5 of 5

13. Cioffi JA, Van Blerkom J, Antczak M, Shafer A, Wittmer S, et al. (1997) The expression of leptin and its receptors in pre-ovulatory human follicles. Mol Hum Reprod 3: $467-472$

14. Fedorcsák P, Storeng R, Dale PO, Tanbo T, Torjesen $P$, et al. (2000) Leptin and leptin binding activity in the preovulatory follicle of polycystic ovary syndrome patients. Scand J Clin Lab Invest 60: 649-655

15. Takikawa S, Iwase A, Goto M, Harata T, Umezu T, et al. (2010) Assessment of the predictive value of follicular fluid insulin, leptin and adiponectin in assisted reproductive cycles. Gynecol Endocrinol 26: 494-499.

16. Asimakopoulos B, Nikolettos N, Papachristou DN, Simopoulou M, Al-Hasan S, et al. (2005) Follicular fluid levels of vascular endothelial growth factor and leptin are associated with pregnancy outcome of normal women participating in intracytoplasmic sperm injection cycles. Physiol Res 54: 263-270.
17. Bützow TL, Moilanen JM, Lehtovirta M, Tuomi T, Hovatta O et al. (1999) Serum and follicular fluid leptin during in vitro fertilization: relationship among leptin increase, body fat mass, and reduced ovarian response. J Clin Endocrino Metab 84: 3135-3139.

18. Moschos S, Chan JL, Mantzoros CS (2002) Leptin and reproduction: a review. Fertil Steril 77: 433-444.

19. Anifandis G, Koutselini E, Louridas K, Liakopoulos V, Leivaditis K, et al. (2005) Estradiol and leptin as conditional prognostic IVF markers. Reproduction 129 531-534.

20. Lau CP, Ledger WL, Groome NP, Barlow DH, Muttukrishna S (1999) Dimeric inhibins and activin $A$ in human follicular fluid and oocyte-cumulus culture medium. Hum Reprod 14: 2525-2530.

21. Woodruff TK (1998) Regulation of cellular and system function by activin Biochem Pharmacol 55: 953-963. 